\title{
The comparative effects of small geographic range and population decline on the adult sex ratio of threatened bird species
}

\author{
J. C. VENABLES and M. de L. BROOKE
}

\begin{abstract}
Summary
Although the factors associated with adult sex ratio (ASR) skew in threatened species are rarely identified, ASRs of threatened species appear to be more male-skewed with increasing severity of threat. In this study we investigate whether the ASRs of species classified as threatened because of decline are significantly different from those threatened because of small range. Despite previous studies suggesting an association between male-skewed ASRs and population decline, our results show that ASRs may be more male-skewed in species classified as threatened because of small range. Although selection would be expected to purge dispersal genotypes from isolated populations, our finding could result from an imbalance between immigration and emigration rates of species with small ranges. Future research should examine rates of emigration and immigration in species with small global ranges.
\end{abstract}

\section{Introduction}

Previous research has shown that the adult sex ratios (ASR) of populations of globally threatened birds are more male-skewed the more severe the IUCN threat classification (Donald 2007). In most cases the Red List criteria (IUCN 2001) used to classify a species as threatened include either population decline or small range, and sometimes both.

Previous studies suggest that increasing male-skews in ASR may be related to population decline, as seen in the Seychelles Magpie-Robin Copsychus sechellarum (Gerlach and Le Maitre 2001) and populations of Capercaillie Tetrao urogallus (Helle et al. 1999, Wilkinson et al. 2002). Interestingly, in Capercaillie as populations stabilised so did the skew in ASR, which returned to roughly equal but not to the former female-skew (Eaton et al. 2007). In some cases a skew in ASR has the potential to contribute to population decline. For example, egg loss and infanticide, as a result of aggressive nest intrusions by unpaired males, have been observed in male-skewed populations of Nazca Booby Sula granti (Anderson et al. 2004) and Humboldt Penguin Spheniscus humboldti (Taylor et al. 2001). Venables (2012) has shown that a male-skewed population of a monogamous species is more prone to extinction than the same population with an equal ASR, most likely because of the difference in productivity of the two populations.

Small, isolated populations or species with small geographic ranges may acquire and/or face enhanced skews in ASR through dispersal, as the dispersing sex is likely to leave the range more often and therefore be lost from the population (Dale 2001). This was shown to be the case in an Ortolan Bunting Emberiza hortulana population, where continued dispersal of females and a lack of immigration of dispersing females led to a male-skew in ASR (Steifetten and Dale 2006). However, where there is little or no immigration into a population, 
such as in isolated populations or in species with very small geographic ranges, selection should favour natal philopatry as only those females that stay and breed in their natal areas will contribute offspring to the population (Dale 2001). But when habitat fragmentation begins, increased dispersal distances may be selected so that dispersers can bridge the gaps between populations (Matthysen et al. 1995) or in order for individuals to find more favourable fragments further away, when born into fragments that are small and where resources are limited (Travis and Dytham 1999, Schtickzelle and Baguette 2003, Schtickzelle et al. 2006, Hui et al. 2012). Hence, it appears that there are a multitude of selection pressures acting on the natal dispersal of birds.

Small populations with little or no immigration will experience some degree of inbreeding and potentially the spread of deleterious alleles. If these alleles exist on the sex chromosomes then we might expect their impact to be greatest on the heterogametic sex, the female in birds, thereby contributing to their generally higher mortality rates and a skewed ASR (Liker and Székely 2005, Li et al. 2008, although see Lee et al. 2002).

Although both small range and population decline could mediate the association between ASR and threat status, an association with decline seems more likely, as to some degree selection must act against female natal dispersal in small, isolated, but stable, populations. This putative relationship with decline may be causal, either with ASR skew leading to population decline, or with population decline leading to ASR skew. Alternatively, it may be caused by other factors, for instance, introduced predators. When such predators were listed as a major threat to birds, the species concerned had more male-skewed ASRs than those for which it was not (Donald 2007). In this study we ask whether ASRs are significantly different for species classified as threatened because of decline or small range and predict that ASRs will be more male-skewed in species classified as threatened because of decline.

\section{Methods}

A database on the ASRs (calculated as proportion of males) of over 200 populations of birds, previously collected by Donald (2007), was the starting point of this study. The database was produced by conducting literature searches on Web of Science, Google Scholar and SORA and by checking through reference lists in each study identified (Donald 2007). We updated this database with more recent studies on population ASRs. In total, 226 estimations of population ASR were included, encompassing 187 species. In $60 \%$ of these estimates capture bias was taken into account, most often by recording the entire population. In the remaining $40 \%$ of ASR estimates capture bias was not taken into account, so, if males were more likely to be caught than females, an artificial skew in ASR towards males would be generated. This difference in the degree of capture bias between estimates is more likely to obscure significant results than lead to Type I error. In this study an ASR of 0.5 indicates a balanced sex ratio. Values above 0.5 indicate a male-skew and values below 0.5 indicate a female-skew.

Data on the IUCN Red List classification of each species in the dataset were obtained from the BirdLife Data Zone (http://www.birdlife.org/datazone/home) in 2009 for data collected previously by Donald (2007) and 2012 for more recent studies. For information on the criteria underlying these classifications see IUCN (2001). Detailed information about the reasons for each species' classification was provided by BirdLife and also recorded. Those species with an IUCN classification of Least Concern were removed from the dataset, leaving only those with classifications of Near Threatened, Vulnerable, Endangered or Critically Endangered. The $4 \mathbb{I}$ species represented in the reduced dataset yielded 47 ASR studies (Table $\mathrm{S}_{1}$ in the online supplementary materials). For the five species yielding more than one study, the studies were separated in time and/or space, and considered as independent data points.

Clearly the IUCN classification of a species in 2009 (or 2012) need not be the same as its IUCN classification when its study in the ASR database was published. To address this problem, a variable was included in the analysis which reflected the accuracy of the IUCN classification at the 
time of our study. This will be referred to as the classification accuracy variable and had four possible levels:

i Species whose IUCN classification has not changed since an ASR study predating 1999. This level was assigned to the four studies concerning species whose IUCN classification in 2009 was the same as its IUCN classification in the year the ASR study was published when that study was published before 1998. (IUCN classification histories were available from the BirdLife Data Zone, although criteria used for classification were not readily available),

ii Species whose IUCN classification has changed since an ASR study after 1998. The definition used in (i) may have introduced biases, as species that were not declining may have been more likely to retain their IUCN classification between years, whilst populations in decline may have moved more quickly between IUCN classifications. Level ii was assigned to the five studies concerning species whose IUCN classification changed between an ASR study published after 1998 and 2008. We considered that, over a period of 10 years, the basis for a species' threat status would remain similar although the actual status might have altered.

iii Species without change in IUCN classification since an ASR study after 1998. The assignment of the 18 species, 20 studies, to either small range or decline categories is likely to be the most accurate.

iv Species whose IUCN classification has changed since an ASR study prior to 1999. The assignment of the 18 species to either small range or decline categories is likely to be the least accurate.

For each species, its IUCN Red List criterion was used to assign it to one of two groups - 'small range' or 'decline' (Table S2). Where criteria for both small range and decline were cited in the species' classification, the criterion leading to the highest threat classification was used to assign the species to a group (analysis 1 ).

In a number of cases, a species was placed in the small range category although the population was in fact in decline (Hawaiian Akepa Loxops coccineus; two population ASRs analysed for this species), Black-eared Miner Manorina melanotis, Elepaio Chasiempis sandwichensis, I'iwi Vestiaria coccinea, Juan Fernández Firecrown Sephanoides fernandensis, Reunion Cuckooshrike Coracina newtoni, Taita Thrush Turdus helleri, Waved Albatross Phoebastria irrorata, Whitewinged Nightjar Caprimulgus candicans and Yellow-eyed Penguin Megadyptes antipodes). In these instances, although the populations were considered in decline, all, or the majority of the IUCN Red List criteria responsible for the threat classifications referred specifically to small range and not population decline. In a second analysis (analysis 2) these species were moved to the decline category and the analysis was redone, so that the small range category contained only those populations that were considered stable, increasing or fluctuating, and the decline category contained all species in decline, regardless of range size.

In one instance (Galapagos Hawk Buteo galapagoensis) the Red List criteria did not specifically refer to population decline or small range but the species was thought to have a stable population of very low numbers in 2009, and a large range. The species was assigned to the decline category on the basis that its ASR study was published in 1980 and therefore it was possible that, when the study was published, the species was in decline, resulting in the low population numbers recorded in the BirdLife Data Zone in 2009.

Once species had been categorised it became clear that the small range category contained far more species with severe IUCN classifications (Critically Endangered or Endangered) than the decline category (which contained mostly species classified as Vulnerable). As Donald (2007) showed in his analysis of a large part of the present updated dataset, degree of skew in ASR appeared to be associated with IUCN classification, becoming more male-skewed in more severely threatened species. Also it was apparent that most species with a small range were island species, 
populations of which may suffer from the introduction of predators, another factor associated with ASR skew in threatened species (Donald 2007). Therefore, when we conducted linear modelling, IUCN classification and island/mainland were included as additional factors. Island/mainland was defined as 'island' (oceanic islands) and 'mainland' (mainland areas and islands located on the continental shelf). New Zealand and surrounding islands were considered oceanic islands as indigenous mammals have not existed there for millions of years. IUCN classification terms were 'Near Threatened', 'Vulnerable', 'Endangered' or 'Critically Endangered'. The two other factors included in the model were category (small range/decline) and classification accuracy (IUCN classification 'the same - $\mathrm{i}^{\prime}$, 'study published after 1998 - ii', 'both - iii' or 'neither - iv'). ASR was the dependent variable. As the ASR estimates were calculated as proportions, the data were arcsine transformed prior to linear modelling. Parameter estimates were back-transformed after analyses. In analysis 1, we fitted models for all possible combinations of the four main effects and the interaction of three factors (island/mainland, IUCN classification and classification accuracy) with the factor category (small range/decline). The model set included 35 models, including the null model and the maximal model of ASR category ${ }^{*}$ (island/mainland + IUCN classification + classification accuracy). In analysis 2, it was not possible to analyse the interaction between category (small range/decline) and island/mainland, since all species in the small range category lived on islands. Instead the maximal model used was ASR $\sim$ island/mainland + category ${ }^{*}$ (IUCN classification + classification accuracy). The model set included 26 models, including the null model and the maximal model. Initially we checked whether the maximal models met the assumptions of a GLM using various diagnostic plots. The two maximal models were compared to all possible reduced models using the program MuMIn in R (Barton 2012). The most appropriate model was selected by assessment of the Akaike Information Criterion (AICc) and Akaike weights $\left(w_{i}\right)$ (see Burnham and Anderson 2002). Models with low AICc values were considered to have stronger support from the data. The model-averaged parameter estimates given in the results were averaged over all models in which the parameter was included. This may bias the estimates away from zero.

\section{Results}

Species in the small range category had a higher (more male-skewed) mean ASR than those in the decline category (Table $\mathrm{I}$ ). The best supported model in analysis $\mathrm{I}$ included category (small range/ decline) and the interaction between category and island/mainland (Table 2). It was not possible to analyse this interaction in analysis 2, where the model containing island/mainland alone had the lowest AICc value, since all species in the small range category lived on islands. Had this analysis been possible then the result found in analysis I might have been repeated, as the model containing category (small range/decline) alone had some support in analysis 2, suggesting that it did explain some variation in ASR (Table 2). Category (small range/decline) appeared to be better able to explain variation in ASR than IUCN classification, which only appeared in one

Table 1 . Basic statistics of the data used in analyses 1 and 2, for all species (regardless of classification accuracy variable), and for those species included in classification accuracy levels i and iii, and ii and iii only. Classification accuracy level iii indicates the most accurate data. Classification accuracy level iv (the least accurate data) is only included in 'All species'. Mean ASR \pm standard deviation (sample size) for the categories, decline and small range, are shown. ASR values above 0.5 indicate a male-skew.

\begin{tabular}{llllll}
\hline & Analysis 1 & & & Analysis 2 & \\
\cline { 2 - 3 } \cline { 5 - 6 } & Decline & Small Range & & Decline & Small Range \\
\hline $\begin{array}{lllll}\text { All species } \\
\begin{array}{l}\text { IUCN classification the same } \\
\text { (i and iii) }\end{array}\end{array}$ & $0.58 \pm 0.15(23)$ & $0.65 \pm 0.11(24)$ & & $0.59 \pm 0.14(34)$ & $0.68 \pm 0.12(13)$ \\
$\begin{array}{l}\text { Study published after 1998 } \\
\text { (ii and iii) }\end{array}$ & $0.58 \pm 0.19(12)$ & $0.67 \pm 0.11(13)$ & & $0.60 \pm 0.17(19)$ & $0.73 \pm 0.09(6)$ \\
\hline
\end{tabular}


Table 2. Data on AICc values and AICc weights $\left(w_{i}\right)$ for models with a $\Delta$ AICc of less than 4 arising from the maximal model ASR category* (island/mainland+IUCN classification+classification accuracy), for the dataset containing all species. 'N/A' - the model did not have a $\triangle \mathrm{AICc}$ of less than 4 in this analysis or the model was not included in the analysis (analysis 2 only). Category refers to small range or decline.

\begin{tabular}{|c|c|c|c|c|c|c|c|}
\hline \multirow[t]{2}{*}{ Model } & \multirow[t]{2}{*}{ Df } & \multicolumn{3}{|c|}{ Analysis 1} & \multicolumn{3}{|c|}{ Analysis 2} \\
\hline & & $\mathrm{AICc}$ & $\triangle \mathrm{AICc}$ & $w_{i}$ & $\mathrm{AICc}$ & $\Delta \mathrm{AICc}$ & $w_{i}$ \\
\hline $\begin{array}{l}\text { Category + Island/Mainland + } \\
\text { Category*Island/Mainland }\end{array}$ & 5 & -48.3 & $\mathrm{O}$ & 0.35 & $\mathrm{~N} / \mathrm{A}$ & $\mathrm{N} / \mathrm{A}$ & N/A \\
\hline Island/Mainland & 3 & $-47 \cdot 9$ & 0.46 & 0.27 & $-47 \cdot 9$ & $\mathrm{O}$ & 0.40 \\
\hline Category + Island/Mainland & 4 & $-45 \cdot 7$ & 2.58 & 0.10 & -46.5 & 1.35 & 0.20 \\
\hline Island/Mainland + IUCN & 6 & -45.1 & 3.27 & 0.07 & -45.1 & 2.81 & 0.10 \\
\hline Category & 3 & $\mathrm{~N} / \mathrm{A}$ & N/A & N/A & -44.6 & 3.25 & 0.08 \\
\hline
\end{tabular}

model with a $\triangle$ AICc less than 4 (Table 2). IUCN classification also did not interact with category (small range/decline) to explain variation in ASR. The classification accuracy variable was not included in any model with a $\triangle$ AICc less than 4 , suggesting that either noise in the whole dataset was limited or that this noise was still present in the data with higher classification accuracy levels (e.g. level iii).

When model-averaging was undertaken, the confidence interval for island/mainland did not contain zero in either dataset and the confidence interval for the interaction term island/mainland and category (small range/decline) did not contain zero in analysis I (Table 3). There were two models with high AICc weights $\left(w_{i}\right)$ in both analyses (Table 4$)$. The model containing island/ mainland alone had a high AICc weight in both analysis $1\left(w_{i}=0.273\right)$ and $2\left(w_{i}=0.396\right)$ and the confidence interval for this parameter estimate did not contain zero. In analysis 1 , the model with the highest AICc weight $\left(w_{i}=0.345\right)$ contained category (small range/decline), island/mainland and the interaction of these two terms. None of the parameter estimate confidence intervals contained zero in this model. The second model with a high AICc weight $\left(w_{i}=0.201\right)$ in analysis 2 contained category (small range/decline) and island/mainland (but not the interaction between these two terms, as this could not be analysed in analysis 2). Only the confidence interval for island/mainland did not contain zero in this model (Table 4).

This would suggest that, in combination, island/mainland and category (small range/decline) are able to explain a significant amount of variation in ASR in the datasets. Overall, these results suggest that threatened species located on islands have a more male-skewed ASR than those located on mainland (Figure 1a), that species classified as threatened because of small range show more male-skewed ASRs than those in decline (Figure $\mathrm{Ib}$ ), and this latter result is primarily because, among mainland species, those classified as threatened because of small range have a more male-skewed ASR than those classified as threatened because of decline (Figure Ic).

\section{Discussion}

IUCN threat classification was not the best predictor of ASR skew (Table 2), nor did it interact significantly with category (small range/decline) to explain differences in ASR skew between species. Rather, the results suggest that ASR is more male-skewed in island species than mainland species, and in those species classified as threatened due to small range than in those threatened due to decline. Models containing island/mainland alone or in combination with category (small range/decline) had the lowest AICc values. The significance of island/mainland accords with Donald's (2007) demonstration that those species threatened from introduced predators had higher ASRs than those not. This is because island/mainland can be considered a partial proxy for threat from introduced predators, as island species are often impacted by introduced mammalian predators. However, our study also showed that ASRs were more male-skewed in mainland species classed as threatened because of small range than in those in decline, which was unexpected. While ASR skew has frequently been associated with 
Table 3. Model averaged parameter estimates from a) analysis 1 and b) analysis 2 . The parameter estimates were averaged over all models in which the parameter was included. This may bias the estimates away from zero. "Estimate" - the parameter estimate. "SE" - standard error (these have been adjusted, as described in Bartón 2012). "CL" - confidence limit, set at 2.5 and $97.5 \%$ to give a $95 \%$ confidence interval. Those in bold indicate significant parameters (excluding the intercept).

\begin{tabular}{|c|c|c|c|c|c|}
\hline a) & $\begin{array}{l}\text { Number of models } \\
\text { containing variable }\end{array}$ & Estimate & SE & $2.5 \% \mathrm{CL}$ & $97.5 \% \mathrm{CL}$ \\
\hline Intercept & 35 & 0.534 & 0.060 & 0.417 & 0.649 \\
\hline Category (small range) & 27 & 0.020 & 0.109 & -0.005 & 0.120 \\
\hline Island/Mainland (Island) & 22 & 0.020 & 0.062 & $<0.001$ & 0.069 \\
\hline $\mathrm{IUCN}(\mathrm{EN})$ & 22 & 0.009 & 0.127 & -0.008 & 0.022 \\
\hline IUCN (NT) & 22 & $<0.001$ & 0.204 & -0.032 & 0.037 \\
\hline IUCN (VU) & 22 & -0.006 & 0.139 & -0.043 & 0.003 \\
\hline Classification accuracy (both) & 22 & 0.007 & 0.075 & -0.004 & 0.052 \\
\hline Classification accuracy (criteria same) & 22 & $<-0.001$ & 0.101 & -0.045 & 0.033 \\
\hline Classification accuracy (neither) & 22 & 0.003 & 0.075 & -0.009 & 0.038 \\
\hline $\begin{array}{l}\text { Category (small range)*Island/ } \\
\text { Mainland (Island) }\end{array}$ & 9 & -0.048 & 0.104 & -0.171 & $<-0.001$ \\
\hline Category (small range) ${ }^{*} \mathrm{IUCN}(\mathrm{EN})$ & 9 & $<-0.001$ & 0.127 & -0.070 & 0.052 \\
\hline Category (small range) ${ }^{*} \mathrm{IUCN}(\mathrm{NT})$ & 9 & -0.008 & 0.204 & -0.220 & 0.094 \\
\hline Category (small range) ${ }^{*}$ IUCN (VU) & 9 & 0.030 & 0.139 & -0.010 & 0.185 \\
\hline $\begin{array}{l}\text { Category (small range) }{ }^{*} \text { Classification } \\
\text { accuracy (both) }\end{array}$ & 9 & -0.001 & 0.181 & -0.142 & 0.102 \\
\hline $\begin{array}{l}\text { Category (small range)* Classification } \\
\text { accuracy (criteria same) }\end{array}$ & 9 & -0.018 & 0.237 & -0.319 & 0.106 \\
\hline Category (small range) ${ }^{*}$ Classification & 9 & -0.008 & 0.182 & -0.188 & 0.070 \\
\hline
\end{tabular}

\section{b)} accuracy (neither)

Number of models

Estimate SE $\quad 2.5 \% \mathrm{CL} \quad 97.5 \% \mathrm{CL}$ containing variable

\begin{tabular}{|c|c|c|c|c|c|}
\hline Intercept & 26 & 0.558 & 0.058 & 0.445 & 0.668 \\
\hline Category (small range) & 18 & 0.004 & 0.058 & -0.003 & 0.030 \\
\hline Island/Mainland (Island) & 13 & 0.012 & 0.048 & $<0.001$ & 0.041 \\
\hline IUCN (EN) & 16 & 0.001 & 0.058 & -0.007 & 0.020 \\
\hline IUCN (NT) & 16 & $<-0.001$ & 0.086 & -0.034 & 0.024 \\
\hline IUCN (VU) & 16 & -0.007 & 0.063 & -0.043 & 0.001 \\
\hline Classification accuracy (both) & 16 & 0.008 & 0.073 & -0.003 & 0.053 \\
\hline Classification accuracy (criteria same) & 16 & $<-0.001$ & 0.099 & -0.039 & 0.036 \\
\hline Classification accuracy (neither) & 16 & 0.002 & 0.073 & -0.009 & 0.036 \\
\hline $\begin{array}{l}\text { Category (small range) }{ }^{*} \text { Island/Mainland } \\
\text { (Island) }\end{array}$ & $\mathrm{O}$ & N/A & N/A & N/A & $\mathrm{N} / \mathrm{A}$ \\
\hline Category (small range)*IUCN (EN) & 6 & -0.001 & 0.114 & -0.064 & 0.036 \\
\hline Category (small range) ${ }^{*} \mathrm{IUCN}(\mathrm{NT})$ & 6 & -0.012 & 0.182 & -0.202 & 0.059 \\
\hline Category (small range) ${ }^{*} \mathrm{IUCN}(\mathrm{VU})$ & 6 & 0.057 & 0.138 & $<-0.001$ & 0.239 \\
\hline $\begin{array}{l}\text { Category (small range) }{ }^{*} \text { Classification } \\
\text { accuracy (both) }\end{array}$ & 6 & 0.009 & 0.170 & -0.056 & 0.172 \\
\hline $\begin{array}{l}\text { Category (small range) }{ }^{*} \text { Classification } \\
\text { accuracy (criteria same) }\end{array}$ & 6 & -0.010 & 0.218 & -0.252 & 0.107 \\
\hline $\begin{array}{l}\text { Category (small range) }{ }^{*} \text { Classification } \\
\text { accuracy (neither) }\end{array}$ & 6 & $<-0.001$ & 0.157 & -0.109 & 0.076 \\
\hline
\end{tabular}

decline (Helle et al. 1999, Gerlach and Le Maitre 2001, Wilkinson et al. 2002, Smith and Iverson 2006, Eaton et al. 2007, Grüebler et al. 2008, Lehikoinen et al. 2008, Brooke et al. 2012), it has rarely been documented in relation to small range (Cooper and Walters 2002, Steifetten and Dale 2006). 
Table 4. Details of models with AICc weights greater than 0.10o. "Estimate" - the parameter estimate. "SE" - standard error (these have been adjusted, as described in Bartón, 2012). "CL" - confidence limit, set at 2.5 and $97.5 \%$ to give a $95 \%$ confidence interval. Those in bold indicate significant parameters (excluding the intercept).

a) Analysis 1. Model: Category * Island/Mainland. AICc: -48.3 ; delta: o; weight: 0.345.

\begin{tabular}{lclrr}
\hline Parameter & Estimate & SE & $2.5 \%$ CL & \multicolumn{1}{c}{$97.5 \%$ CL } \\
Intercept & 0.509 & 0.037 & 0.436 & 0.582 \\
Category (small range) & $\mathbf{0 . 0 3 4}$ & $\mathbf{0 . 0 8 6}$ & $<\mathbf{0 . 0 0 1}$ & $\mathbf{0 . 1 2 1}$ \\
Island/Mainland (Island) & $\mathbf{0 . 0 3 1}$ & $\mathbf{0 . 0 5 6}$ & $\mathbf{0 . 0 0 5}$ & $\mathbf{0 . 0 8 1}$ \\
Category (small range) * Island/Mainland (Island) & $\mathbf{- 0 . 0 4 8}$ & $\mathbf{0 . 1 0 0}$ & $\mathbf{- 0 . 1 6 5}$ & $\mathbf{- 0 . 0 0 1}$ \\
\hline
\end{tabular}

b) Analysis 1 and 2. Model: Island/Mainland. The data used in this model were the same for analysis 1 \& 2, however, the model's delta AICc and AICc weight differ between the analyses due to the different maximal models used. AICc: -47.9 (analysisı \& analysis 2); delta: 0.46 (analysis 1) and o (analysis 2); weight: 0.273 (analysis 1) and 0.396 (analysis 2).

\begin{tabular}{lllcc}
\hline Parameter & Estimate & SE & $2.5 \% \mathrm{CL}$ & $97 \cdot 5 \% \mathrm{CL}$ \\
Intercept & 0.544 & 0.035 & 0.476 & 0.611 \\
Island/Mainland & $\mathbf{0 . 0 1 4}$ & $\mathbf{0 . 0 4 3}$ & $\mathbf{0 . 0 0 1}$ & $\mathbf{0 . 0 4 0}$
\end{tabular}

c) Analysis 2. Model: Category + Island/Mainland. AICc: -46.5; delta: 1.35; weight: 0.201.

\begin{tabular}{lclcc}
\hline Parameter & Estimate & SE & $2.5 \%$ CL & $97.5 \%$ CL \\
Intercept & 0.544 & 0.035 & 0.476 & 0.611 \\
Category (small range) & 0.003 & 0.050 & -0.002 & 0.022 \\
Island/Mainland & $\mathbf{0 . 0 1 0}$ & $\mathbf{0 . 0 4 8}$ & $<\mathbf{0 . 0 0 1}$ & $\mathbf{0 . 0 3 6}$ \\
\hline
\end{tabular}

Small ranges have a higher percentage of the total area close to the range boundary than do large ranges. If rates of immigration/emigration play a role in causing ASR skew then we might expect populations with small ranges to have a more male-skewed ASR than populations with varying range sizes that are declining. Although the causes of ASR skew are not known in many species, some evidence suggests that immigration rates are more important to population growth than factors affecting survival of individuals (Schaub et al. 2012). This was shown in an isolated, range boundary population of Yellow-headed Blackbird Xanthocephalus xanthocephalus where low immigration rates and still high male natal dispersal were thought to be causing population decline (Ward 2005). But this skew in ASR in small-range species need not be associated with short-term declines. For instance, if ASR skew were the result of higher male philopatry, then changes in the age structure and size of the population need not result in a reduction in skew, as more males than females would always be recruited to the population. This would clearly only occur in isolated populations without immigration.

For the group of species located on the mainland and considered to be in decline, the mean ASR was 0.51 (Figure Ic) (i.e. there were approximately as many males as females in the populations). However, this need not imply that skews in ASR do not affect mainland species, either those in decline or those considered 'Least Concern'. If ASR skews are more pronounced towards range edges then we might expect most populations in species with larger ranges to have a roughly equal ASR, even if those species are in decline. However, towards range edges ASR skew may be detected. In declining species, as range begins to contract, these ASR skews at range boundaries may start to have an effect on the conservation risk of the species.

In this analysis it was difficult to separate the effects of small range and decline, as these were not mutually exclusive. This was apparent in the data, with a number of species classified as threatened due to small range also in decline. The seemingly frequent combination of these two threats in species' Red List criteria for all IUCN classifications would suggest that they often go hand in hand. This may explain why the difference in mean ASR between these two categories was not significant in species located on islands. Rerunning this analysis with a substantially larger dataset would be of use, but this is contingent on the availability of many more estimates of ASR in threatened species. 

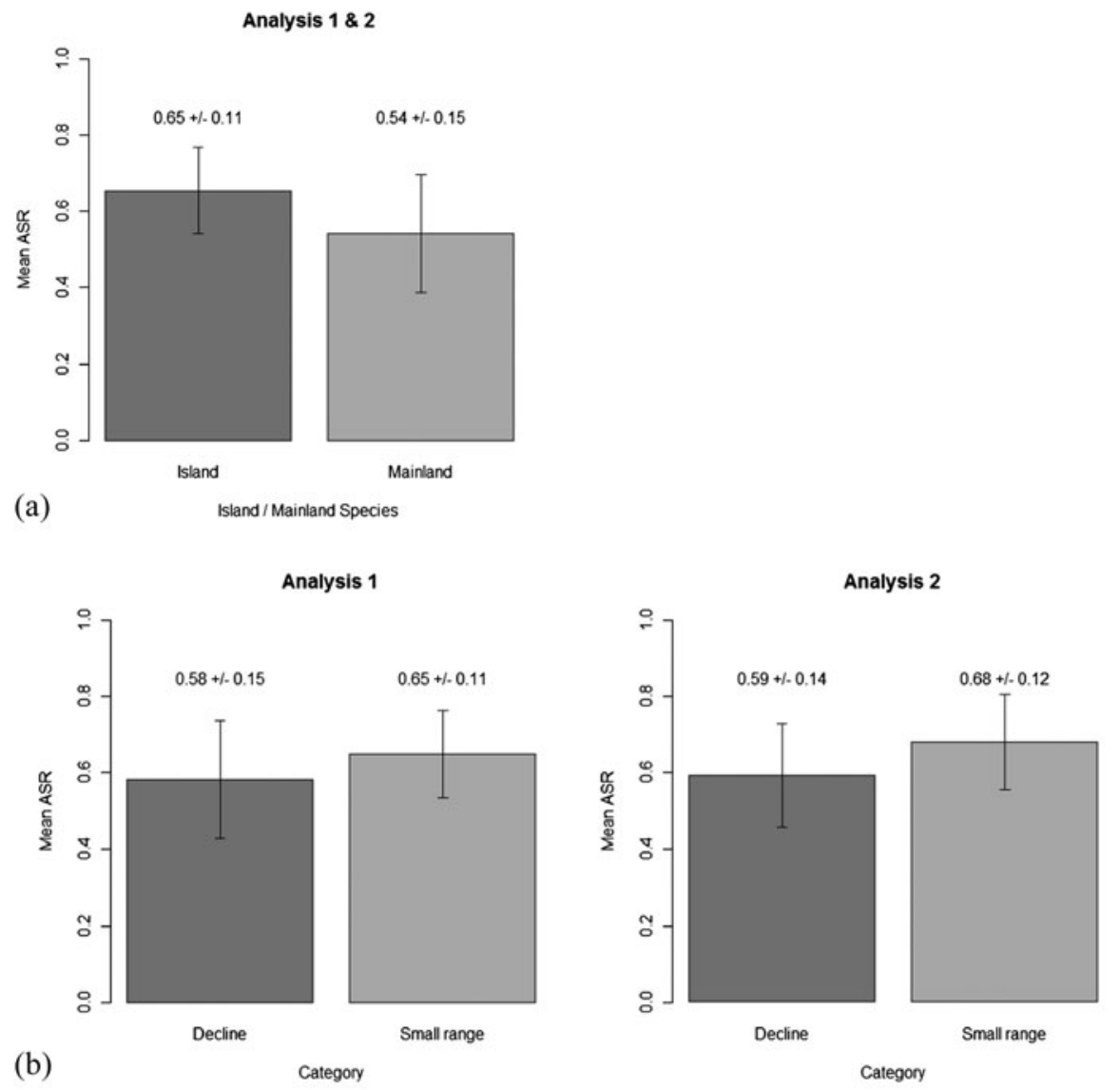

Analysis 1
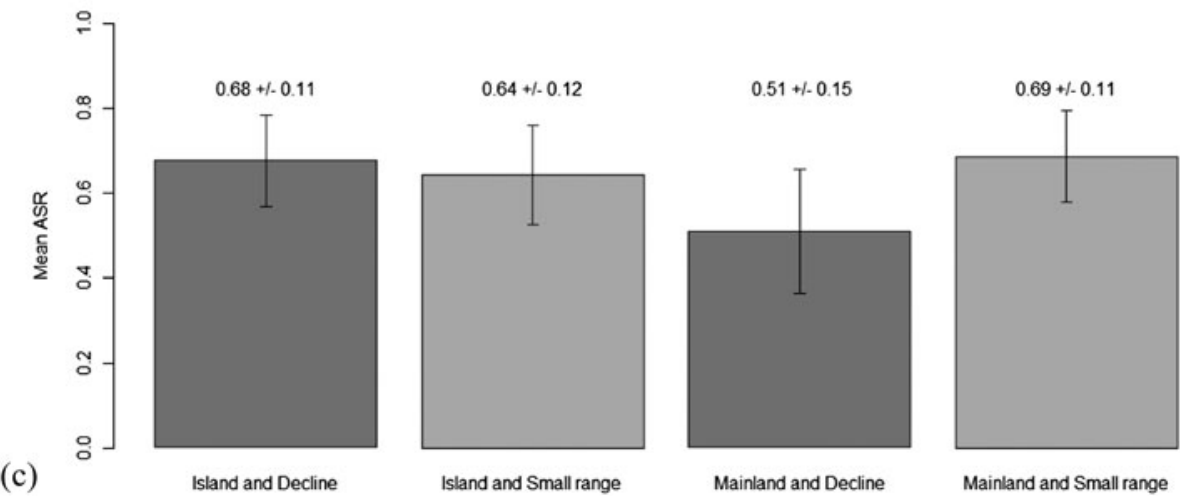

Figure 1. Mean adult sex ratio (ASR) \pm I standard deviation of (a) species located on islands $(n=31)$ and on mainland $(n=16)$, (b) species classified as threatened because of decline (analysis $1-n=23$, analysis $2-n=34$ ) or small range (analysis $1-n=24$; analysis $2-n=13$ ) or (c) species classified as threatened because of small range or decline and located on islands (decline $-n=10$, small range $-n=21$ ) or mainland (decline $-n=13$, small range $-n=3$ ) Analysis 1 only. An ASR of above 0.5 indicates a male-skew. The mean ASR \pm 1 standard deviation are shown above each bar. 
The higher weights of models containing category (small range/decline) suggest that the reasons for skews in isolated populations are worth further investigation. Therefore, future research in this area might usefully study emigration rates from threatened populations. Whilst emigration rates have been shown to be lower in isolated populations (Weatherhead and Forbes 1994) they are still high and sex differences in these rates are often not addressed. Without understanding these potential causes of ASR skew in species with small ranges we cannot predict which species may be more susceptible to skews in ASR nor understand how best to manage such species.

In conclusion, our results suggest that threatened species on islands have a more male-skewed ASR than those located on mainland, and that, among the mainland species, those classified as threatened because of small range have a more male-skewed ASR than those classified as threatened because of decline. These results could be explained by dispersal of females out of small, isolated populations. This research has important implications for the conservation and management of threatened species, particularly those with small ranges. Therefore, further research is required into immigration and emigration rates at boundary populations or in small populations that occupy a small range.

\section{Supplementary Material}

The supplementary materials for this article can be found at journals.cambridge.org/bci

\section{Acknowledgements}

The work was undertaken during tenure of a NERC studentship awarded to JCV. Our thanks to Paul Donald for generously providing unfettered access to his database. He, Sheena Cotter, Rhys Green, Bill Sutherland and Rose Thorogood and an anonymous referee provided helpful suggestions in the course of this work.

\section{References}

Anderson, D. J., Porter, E. T. and Ferree, E. D. (2004) Non-breeding Nazca boobies (Sula granti) show social and sexual interest in chicks: behavioural and ecological aspects. Behaviour 141: 959-977.

Barton, K. (2012) Package 'MuMIn'. [online] Available at: $<$ http://cran.r-project.org/web/ packages/MuMIn/MuMIn.pdf> [Accessed 08 July 2012].

Brooke, M. de L., Flower, T. P., Campbell, E. M., Mainwaring, M. C., Davies, S. and Welbergen, J. A. (2012) Rainfall-related population growth and sex ratio change in the Critically Endangered Raso lark Alauda razae. Anim. Conserv. 16: 466-471.

Burnham, K. P. and Anderson, D. R. (2002) Model selection and multimodel inference: a practical information theoretic approach. $2^{\text {nd }}$ edition. New York: Springer-Verlag.

Cooper, C. B. and Walters, J. R. (2002) Experimental evidence of disrupted dispersal causing decline of an Australian passerine in fragmented habitat. Conserv. Biol. 16: $471-478$.

Dale, S. (2001) Female-biased dispersal, low female recruitment, unpaired males, and the extinction of small and isolated bird populations. Oikos 92: 344-356.

Donald, P. F. (2007) Adult sex ratios in wild bird populations. Ibis 149: 671-692.

Eaton, M. A., Marshall, K. B. and Gregory, R. D. (2007) Status of capercaillie Tetrao urogallus in Scotland during winter 2003/4. Bird Study 54: 145-153.

Gerlach, J. and Le Maitre, S. (2001) Sex ratio variation in small island populations of an endangered bird, the Seychelles Magpie Robin, Copsychus sechellarum. Ostrich 72: 114-117.

Grüebler, M. U., Schuler, H., Müller, M., Spaar, R., Horch, P. and Naef-Daenzer, B. (2008) Female biased mortality caused by anthropogenic nest loss contributes to population decline and adult sex ratio of a meadow bird. Biol. Conserv. 141: 3040-3049. 
Helle, P., Kurki, S. and Linden, H. (1999) Changes in the sex ratio of the Finnish capercaillie Tetrao urogallus population. Wildife Biol. 5: 25-31.

Hui, C., Roura-Pascual, N., Brotons, L., Robinson, R. A. and Evans, K. L. (2012) Flexible dispersal strategies in native and non-native ranges: environmental quality and the 'good-stay, bad-disperse' rule. Ecography 35: 1-9.

IUCN (2001) IUCN Red List categories and criteria: Version 3.1. Gland, Switzerland and Cambridge, UK: IUCN Species Survival Commission. IUCN.

Lee, P. L. M., Brain, P. F., Forman, D. W., Bradbury, R. B. and Griffiths, R. (2002) Sex and death: $\mathrm{CHD}_{1} \mathrm{Z}$ associated with high mortality in moorhens. Evolution 56: 2548-2553.

Lehikoinen, A., Christensen, T. K., Öst, M., Kilpi, M., Saurola, P. and Vattulainen, A. (2008) Large-scale change in the sex ratio of a declining eider Somateria mollissima population. Wildlife Biol. 14: 288-301.

Li, W. M., Feng, Y. P., Zhao, R. X., Fan, Y. Z., Affara, N. A., Wu, J. J, Fang, J., Tong, Q., Wang, C. and Zhang, S. J. (2008) Sex ratio bias in early-dead embryos of chickens collected during the first week of incubation. Poultry Sci. 87: 2231-2233.

Liker, A. and Székely, T. (2005) Mortality costs of sexual selection and parental care in natural populations of birds. Evolution 59: 890-897.

Matthysen, E., Adriaensen, F. and Dhondt, A. (1995) Dispersal distances of nuthatches, Sitta europaea, in a highly fragmented forest habitat. Oikos 72: 375-381.

Schaub, M., Reichlin, T. S., Abadi, F., Kéry, M., Jenni, L. and Arlettaz, R. (2012) The demographic drivers of local population dynamics in two rare migratory birds. Oecologia 168 : 97-108.
Schtickzelle, N. and Baguette, M. (2003) Behavioural responses to habitat patch boundaries restrict dispersal and generate emigration-patch area relationships in fragmented landscapes. J. Anim. Ecol. 72 : 533-545.

Schtickzelle, N., Mennechez, G. and Baguette, M. (2006) Dispersal depression with habitat fragmentation in the bog fritillary butterfly. Ecology 87: 1057-1065.

Smith, G. R. and Iverson, J. B. (2006) Changes in sex ratio over time in the endangered iguana Cyclura chychlura inornata. Can. J. Zool. 84: 1522-1527.

Steifetten, O. and Dale, S. (2006) Viability of an endangered population of ortolan buntings: The effect of a skewed operational sex ratio. Biol. Conserv. 132: 88-97.

Taylor, S. S., Leonard, M. L. and Boness, D. J. (2001) Aggressive nest intrusions by male Humboldt penguins. Condor 103: 162-165.

Travis, J. M. J. and Dytham, C. (1999) Habitat persistence, habitat availability and the evolution of dispersal. Proc. R. Soc. Lond. B 266: 723-728.

Venables, J. C. (2012) Factors affecting adult sex ratios in bird populations. $\mathrm{PhD}$ thesis, University of Cambridge, UK.

Ward, M. P. (2005) The role of immigration in the decline of an isolated migratory bird population. Conserv. Biol. 19: 1528-1536.

Weatherhead, P. J. and Forbes, M. R. L. (1994) Natal philopatry in passerine birds: genetic or ecological influences? Behav. Ecol. 5: 426-433.

Wilkinson, N. I., Langston, R. H. W., Gregory, R. D., Gibbons, D. W. and Marquiss, M. (2002) Capercaillie Tetrao urogallus abundance and habitat use in Scotland, in winter 1998-99. Bird Study 49: 177-185.

\section{J. C. VENABLES, M. de L. BROOKE*}

Department of Zoology, University of Cambridge, Downing Street, Cambridge CB2 3 EJ, UK.

*Author for correspondence; email:m.brooke@zoo.cam.ac.uk

Received 12 September 2013; revision accepted 7 June 2014; Published online 19 August 2014 